\title{
Effects of Micro-Electrical Stimulation on Regulation of Behavior of Electro-Active Stem Cells
}

\author{
Ae-Lee $\operatorname{Im}^{1 \dagger}$, Jangho $\mathrm{Kim}^{1 \dagger}$, KiTaek Lim $^{1,2}$, Hoon Seonwoo ${ }^{1}$, Woojae Cho ${ }^{1}$, \\ Pill-Hoon Choung, ${ }^{2}$ Jong Hoon Chung ${ }^{1,3}$ * \\ ${ }^{1}$ Department of Biosystems \& Biomaterials Science and Engineering, Seoul National University, Korea \\ ${ }^{2}$ Department of Oral and Maxillofacial Surgery and Dental Research Institute, School of Dentistry, \\ Seoul National University, Korea \\ ${ }^{3}$ Research Institute for Agriculture and Life Sciences, Seoul National University, Korea \\ ${ }^{t}$ These authors contributed equally to this work
}

Received: April 11 ${ }^{\text {th }}, 2013$; Revised: May $3^{\text {rd }}, 2013$; Accepted: May 24 ${ }^{\text {th }}, 2013$

\section{Abstract}

Purpose: Stem cells provide new opportunities in the regenerative medicine for human or animal tissue regeneration. In this study, we report an efficient method for the modulating behaviors of electro-active stem cells by micro-electric current stimulation (mES) without using chemical agents, such as serum or induction chemicals. Methods: Dental pulp stem cells (DPSCs) were cultured on the tissue culture dish in the mES system. To find a suitable mES condition to promote the DPSC functions, the response surface analysis was used. Results: We found that a working micro-current of $38 \mu \mathrm{A}$ showed higher DPSC proliferation compared with other working conditions. The mES altered the expressions of intracellular and extracellular proteins compared to those in unstimulated cells. The mES with $38 \mu \mathrm{A}$ significantly increased osteogenesis of DPSCs compared with ones without mES. Conclusions: Our findings indicate that mES may induce DPSC proliferation and differentiation, resulting in applying to DPSCs-based human or animal tissue regeneration.

Keywords: Differentiation, Dental pulp stem cell, Micro-electric current stimulation, Proliferation, Response surface analysis

\section{Introduction}

Animal or human stem cells are characterized by their unique ability to differentiate into various types of cells, yielding an important key in the regenerative medicine including animal tissue regeneration (Gronthos et al. 2000; Jo et al. 2007; Richardson et al. 2007; Kim et al. 2009; Wang et al. 2011; Kim et al. 2013). It is therefore important to obtain a large number of stem cells and develop technology for regulating them for stem cellbased biological engineering applications. Stem cells are

\footnotetext{
*Comesponding author: Jong Hoon Chung

Tel: +82-2-880-4601; Fax: +82-2-880-4601

E-mail: jchung@snu.ac.kr
}

exposed on various physical and biochemical environments that enable them to regulate or maintain appropriate biological functions including proliferation in animal or human systems (Gronthos et al. 2000; Jo et al. 2007; Richardson et al. 2007; Kim et al. 2009; Wang et al. 2011; Kim et al. 2013; Lim at al. 2013). In general, the traditional biologists have focused on the behavior of stem cells through 'cocktail' of biochemical factors such as proteins and hormones (Kim et al. 2009). For example, the fetal bovine serum (FBS) which contains well-defined biochemical factors (e.g., growth factor) promotes the function of stem cells (Jo et al. 2007).

It has been known that electrical cues may also influence on the behavior of cells (Falanga et al. 1987; Zhuang et al. 
1997; Zhao et al. 1999; Haddad et al. 2007; Aaron et al. 1999; Aaron et al. 2002; Au et al. 2009; Tandon et al. 2010). Firstly, electrical stimulation (ES) alters the complex interplay between living cells and their physical environments, which plays an integral role in maintaining normal biological functions in the human body (Haddad et al. 2007). Secondly, ES enhances growth factor production in cell culture. This effect has been most studied for production of bone morphogenetic proteins (e.g., BMP-2 and BMP-4), transforming growth factor- $\beta$ (TGF- $\beta$ ), and an insulin-like growth factor 2 (IGF-2) (Aaron et al. 1999; Aaron et al. 2002; Haddad et al. 2007). In particular, ES affects the behaviors of electrically charged molecules, such as receptors, located in cell membrane (Zhao et al. 1999). Thirdly, ES affects the signal transduction cascade in living cells. Many studies have demonstrated that the exposure of living cells to ES can stimulate certain signal transduction cascades, such as the calcium/calmodulin pathway, which is important in the production of intracellular molecules (Falanga et al. 1987; Zhuang et al. 1997).

Recently, Au et al. (2009) reported that the electrical field stimulation enhances phenotype of cardiomyocytes which is one of the types of electro-active cells. In addition, it has been reported that the electrical fields may regulate the behavior of adipose tissue-derived stem cells (Tandon et al. 2010). These studies suggest that the electrical cues may be able to regulate behavior of stem cells, especially on electro-active stem cells. Thus, we can expect that the electrical stimulation would be an effective method to obtain a number of stem cells or regulate behavior of them.

Dental pulp stem cells (DPSCs) can be easily obtained by tooth of animal or human and are a potential cell source for tissue regeneration, because of their remarkable self-renewal capability and multiple differentiation potentials, much like those of bone marrow stem cells (Gronthos et al. 2000; Jo et al. 2007; Wang et al. 2011). In particular, the DPSCs are putatively derived from neural crest cells, suggesting that the DPSCs may be sensitively responded by electric environments for their function (Jo et al. 2007). However, current studies regulating the behavior of DPSCs have still focused on the traditional biotechnology methods, which uses the 'cocktail' of biochemical factors. In this study, we hypothesize that the appropriate electrical cues would regulate the behavior of DPSCs without use of the growth factors. The objective of this study was to investigate suitable conditions of electrical stimulation for regulating behavior of DPSCs, types of electro-active stem cells

\section{Materials and Methods}

\section{In vitro micro-electrical stimulation system}

The micro-electric current supply comprised a potentiometer, controlled timers, and a monitor (Figure 1A). The in vitro micro-electrical stimulation (mES) system consisted of a micro-current supply located next to the $\mathrm{CO}_{2}$ incubator and a $35 \mathrm{~mm}$ tissue culture dish (TCPS) with platinum electrodes in the $\mathrm{CO}_{2}$ incubator (Figure 1).
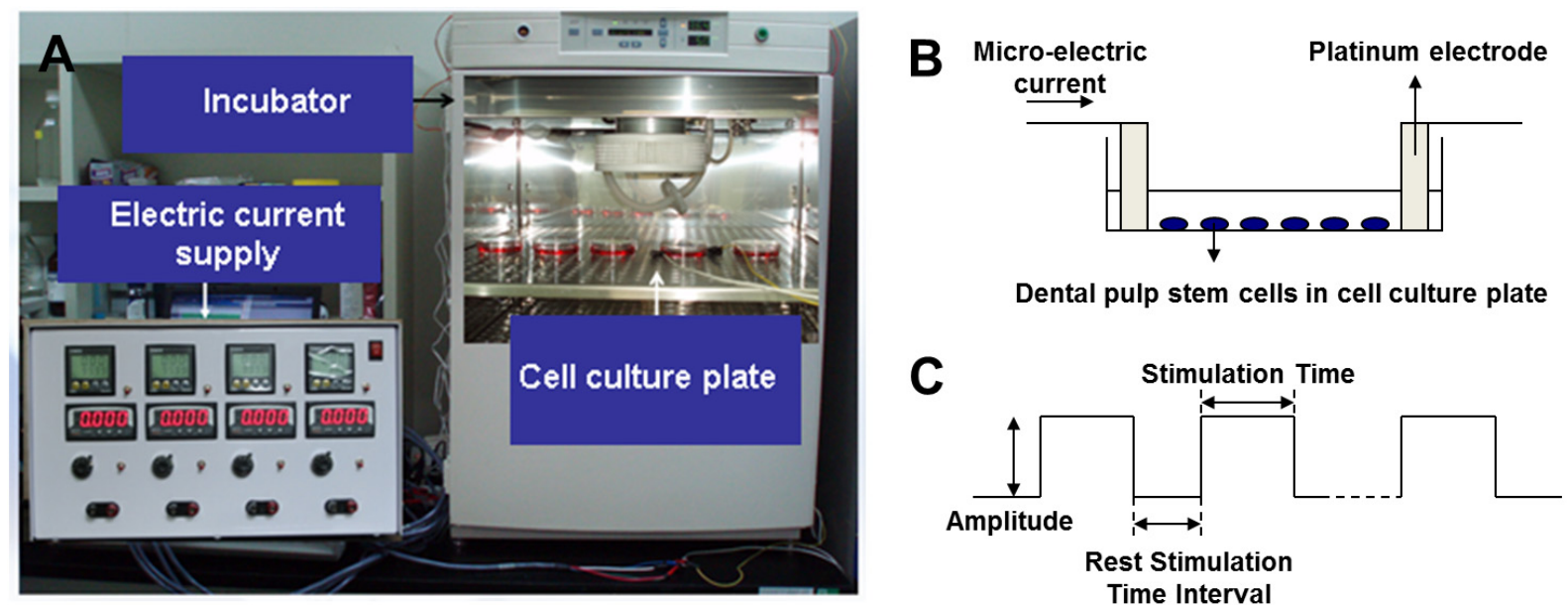

Figure 1. In vitro mES system used in this study. The system consists of a micro-current supply located adjacent to the $\mathrm{CO}_{2}$ incubator and culture plates with platinum electrodes for stimulation in the $\mathrm{CO}_{2}$ incubator. 


\section{Dental pulp stem cell culture}

DPSCs were provided by Prof. PH Choung from the Tooth Bioengineering National Laboratory in the College of Dentistry at Seoul National University. Isolated DPSCs were seeded onto TCPS with alpha-modified Eagle's medium (alpha-MEM; Gibco BRL, Carlsbad, CA, USA) supplemented with $10 \%$ fetal bovine serum (FBS), 2 $\mathrm{mM} / \mathrm{L}$ glutamine, $100 \mathrm{U} / \mathrm{mL}$ penicillin, and $100 \mu \mathrm{g} / \mathrm{mL}$ streptomycin (Gibco BRL, Carlsbad, CA, USA) at $37^{\circ} \mathrm{C}$ in a humidified atmosphere containing $5 \% \mathrm{CO}_{2}$. The culture medium was changed at 2- to 3-day intervals. We electrically stimulated DPSCs between passages 5 and 6 without FBS or induction media (i.e., without use of growth factors) in an in vitro mES system. We also empirically determined the optimal current intensity, stimulation time, and rest stimulation time interval using results of a central composite design and a response surface analysis. DPSCs were stimulated for a total of $2 \mathrm{~h}$ per day (including stimulation and time rest).

\section{Central composite design and response surface analysis to assay the effects of micro-electrical stimulation conditions on proliferation of dental pulp stem cells}

To determine optimal mES parameters, such as current $(\mu \mathrm{A})$, stimulation time (ST_TIME; sec), and rest time (ST_INTV; sec) (Berg 1995; Kim et al. 2006), a central composite design and a response surface analysis were used (Li et al. 2008). The central composite design with five coded levels was applied for optimization. For the three factors of interest, this study used a full 8 factorial design with six axial points and each replication at the center points, totaling in 20 experiments $(8+6+6)$. The data were analyzed using a second-order polynomial equation, and the data were fitted to the equation by a multiple regression procedure. The model equation is as follows (Li et al. 2008):

$$
Y=\beta_{0}+\sum_{i=1}^{k} \beta_{i} \chi_{i}+\sum_{i}^{k} \beta_{i i} \chi_{i}^{2}+\sum_{i<j} \beta_{i j} \chi_{i} \chi_{j}
$$

where $Y$ is the predicted response, $\beta_{0}$ is the intercept term, $\beta_{1}$ is the linear coefficient, $\beta_{i i}$ is the squared coefficient, and $\beta_{i j}$ is the interaction coefficient.

The quality of fit of this model was expressed by the coefficient $R^{2}$, and its statistical significance was determined by an F-test. Statistical analysis of experimental data was performed using SAS software (Version 9.1, SAS Institute Inc., Cary, NC, USA).

\section{Analysis of proliferation of dental pulp stem cells by micro-electrical stimulation}

DPSCs $\left(2 \times 10^{4}\right.$ cells $\left./ \mathrm{mL}\right)$ were seeded on TCPS in the in vitro $\mathrm{mES}$ system. After culturing DPSCs with or without mES, DPSCs proliferation was determined by MTT (3-(4,5-Dimethylthiazol-2-yl)-2,5-diphenyltetrazolium bromide) assay.

\section{Extraction of intracellular and extracellular proteins and SDS-PAGE to analyze protein secretion induced by micro-electrical stimulation}

To obtain intracellular and extracellular proteins, DPSCs $\left(2 \times 10^{4}\right.$ cells $\left./ \mathrm{mL}\right)$ were cultured in the in vitro $\mathrm{mES}$ system. After culturing DPSCs for 2 days with mES, the culture medium was collected and extracted by centrifugation at $3000 \mathrm{G}$ in a Centriprep filter (Millipore, amicon, USA) with a 3-kDa pore size. The DPSCs were lysed in $30 \mu \mathrm{L}$ of NP-40 buffer (50 mM Tris-HCl, pH 8.0, $150 \mathrm{mM} \mathrm{NaCl,} 5$ mM EDTA, 1\% NP-40, and 1 mM PMSF) supplemented with a protease inhibitor cocktail (AMRESCO Inc., USA). The extracted proteins were analyzed by SDS-PAGE.

\section{Western blot analysis}

Total cellular protein was extracted by RIPA lysis buffer (62.5 mM Tris-HCL, 2\% SDS, 10\% glycero, pH 7.5) with added proteinase inhibitor cocktail (Invitrogen, USA). Cell lysates were incubated on ice for $30 \mathrm{~min}$ and then centrifuged at $13,000 \mathrm{rpm}$ for $30 \mathrm{~min}$ at $4{ }^{\circ} \mathrm{C}$. Supernatant (protein lysate) was collected and protein concentration was determined by a micro bicinchoninic acid (BCA) Protein Assay Kit (Bio-rad, Hercules, Calif). 25 $\mu \mathrm{g}$ aliquots of the cell lysates were separated by $8 \%$ SDS-PAGE under reducing conditions. Separated proteins were transferred to a PVDF membrane (Millipore Corporation, Bedford, MA, USA) at $30 \mathrm{~V}$ for $1 \mathrm{~h}$. After blocking with $5 \%$ skim milk in PBST, the membrane were incubated overnight in primary antibody at $4{ }^{\circ} \mathrm{C}$. Primary antibody was purchased from the company (Abcam, Cambridge, MA, USA). Quantification of the Western blot was performed using the Image J software with a normalization of the level of the entire protein. 


\section{Statistical analysis}

Each experiment was repeated at least three times. All data were statistically analyzed using a one-way analysis of variance (ANOVA) and t-test. Statistical significance was set at $p<0.05$.

\section{Results and Discussion}

We first showed that the proliferation of DPSC was sensitive to $\mathrm{mES}$. Since this is the first report on the investigating such effects on the proliferation of DPSCs by electrical stimulation, there was no information regarding the optimal mES parameters. We used a statistical method with an appropriate experimental design to determine the optimal mES conditions for DPSC proliferation, such as current $(\mu \mathrm{A})$, stimulation time (ST_TIME; sec), or rest stimulation time interval (ST_INTV; sec). The central composite design was used to study the variables within the range of -1.68 to 1.68 in relation to DPSC proliferation (Table 1). The design table and corresponding experimental data are shown in Table 2 . The results were analyzed by standard analysis of variance (ANOVA) (Table 3), and the central composite design was fitted with the following second-order polynomial equation:

$$
\begin{aligned}
& Y=2.421+0.102 X_{1}+0.023 X_{2}+0.081 X_{3}-0.009 X_{1}^{2}- \\
& 0.054 X_{1} X_{2}-0.120 X_{2}^{2}-0.109 X_{1} X_{3}-0.005 X_{2} X_{3}-0.001 X_{3}^{2}
\end{aligned}
$$

Table 1. Experimental ranges and levels of independent variables

\begin{tabular}{ccccccc} 
Variables & \multicolumn{5}{c}{ Range and Levels } \\
\cline { 2 - 6 } & -1.682 & -1 & 0 & 1 & 1.682 \\
Rest time $(\mathrm{sec})$ & 9.54 & 30 & 60 & 90 & 110.46 \\
Current $(\mu \mathrm{A})$ & 6.36 & 20 & 40 & 60 & 73.64 \\
\hline Stimulation time $(\mathrm{sec})$ & 3.18 & 10 & 20 & 30 & 36.82 \\
\hline
\end{tabular}

Table 2. Central composite design matrix of three variables in coded and natural units, along with the observed responses (cell

\begin{tabular}{|c|c|c|c|c|c|c|c|}
\hline $\begin{array}{l}\text { Obs. } \\
\text { No. }\end{array}$ & $X_{1}$ & $X_{2}$ & $x_{3}$ & $\begin{array}{l}\text { Rest time } \\
\quad(\mathrm{sec})\end{array}$ & $\begin{array}{l}\text { Current } \\
(\mu \mathrm{A})\end{array}$ & $\begin{array}{l}\text { Stimulation time } \\
\text { (sec) }\end{array}$ & $\begin{array}{l}\text { Cell proliferation } \\
\text { (O.D) }\end{array}$ \\
\hline 1 & -1 & -1 & -1 & 30 & 20 & 10 & 1.861 \\
\hline 2 & -1 & -1 & 1 & 30 & 20 & 30 & 2.223 \\
\hline 3 & -1 & 1 & -1 & 30 & 60 & 10 & 1.987 \\
\hline 4 & -1 & 1 & 1 & 30 & 60 & 30 & 2.424 \\
\hline 5 & 1 & -1 & -1 & 90 & 20 & 10 & 2.401 \\
\hline 6 & 1 & -1 & 1 & 90 & 20 & 30 & 2.422 \\
\hline 7 & 1 & 1 & -1 & 90 & 60 & 10 & 2.408 \\
\hline 8 & 1 & 1 & 1 & 90 & 60 & 30 & 2.311 \\
\hline 9 & 1.682 & 0 & 0 & 9.54 & 40 & 20 & 2.345 \\
\hline 10 & 1.682 & 0 & 0 & 110.46 & 40 & 20 & 2.548 \\
\hline 11 & 0 & 1.682 & 0 & 60 & 6.36 & 20 & 2.102 \\
\hline 12 & 0 & 1.682 & 0 & 60 & 73.64 & 20 & 2.159 \\
\hline 13 & 0 & 0 & 1.682 & 60 & 40 & 3.18 & 2.355 \\
\hline 14 & 0 & 0 & 1.682 & 60 & 40 & 36.82 & 2.580 \\
\hline 15 & 0 & 0 & 0 & 60 & 40 & 20 & 2.432 \\
\hline 16 & 0 & 0 & 0 & 60 & 40 & 20 & 2.425 \\
\hline 17 & 0 & 0 & 0 & 60 & 40 & 20 & 2.421 \\
\hline 18 & 0 & 0 & 0 & 60 & 40 & 20 & 2.413 \\
\hline 19 & 0 & 0 & 0 & 60 & 40 & 20 & 2.406 \\
\hline 20 & 0 & 0 & 0 & 60 & 40 & 20 & 2.411 \\
\hline
\end{tabular}
proliferation (optical density (O.D)) 
Table 3. Analysis of variance for the model

\begin{tabular}{cccccc} 
Sources & DF & Sum of squares & Mean squares & F value & 103.51 \\
\hline Lack of Fit & 5 & 0.048857 & 0.009771 & & $<.0001$ \\
Pure Error & 5 & 0.000472 & 0.000094 & & \\
\hline Total Error & 10 & 0.049329 & 0.004933 & & \\
\hline
\end{tabular}

Mean of response $=2.3317 ; \quad$ Root $M S E=0.07024 ; \quad R^{2}=0.9876$

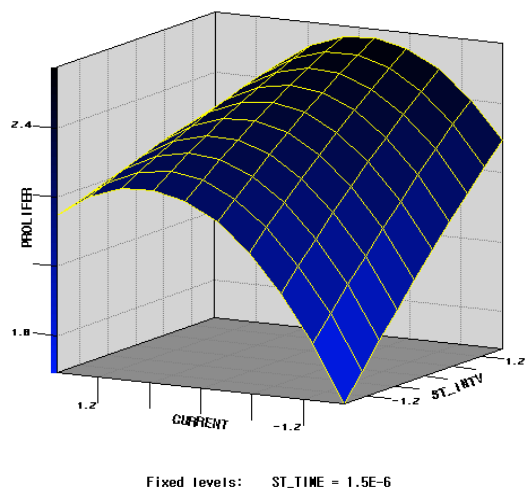

Figure 2. Response surface plots for the effect of current $(\mu \mathrm{A})$ and rest time (ST_INTV: sec) on DPSC proliferation (PROLIFER).

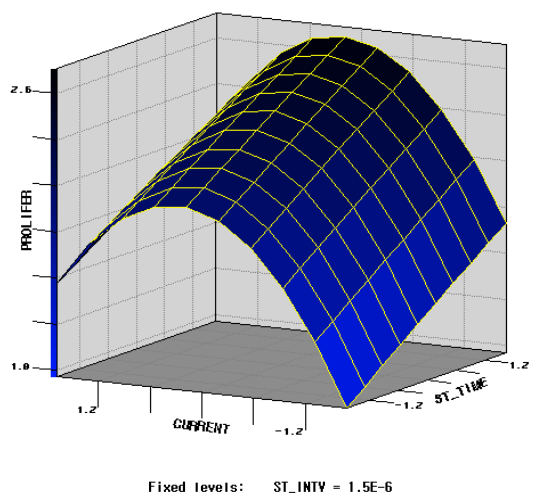

Figure 3. Response surface plots for the effect of stimulation time (ST_TIME: sec) on DPSC proliferation (PROLIFER).

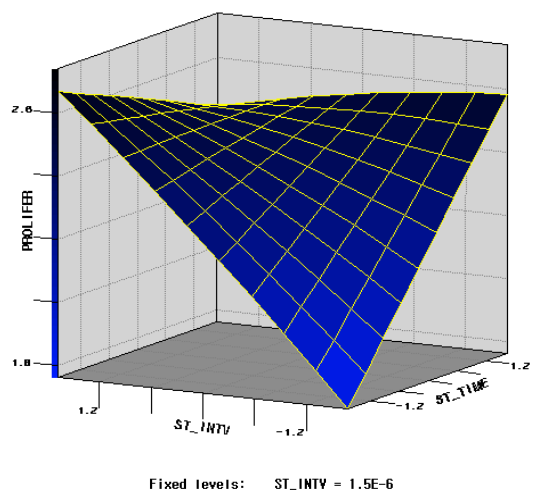

Figure 4. Response surface plots for the effect of rest time (ST_INTV: Sec) and stimulation time (ST_TIME: sec) on DPSC proliferation (PROLIFER). where $Y$ is the cell proliferation (O.D), $X_{1}$ is the rest time (sec), $X_{2}$ is the current intensity $(\mu \mathrm{A})$, and $X_{3}$ is the stimulation time (sec).

The suitability of the model was verified by an $R^{2}$ of 0.9870 and $p<0.0001$. The response surface plots for DPSC proliferation against mES are shown in Figures. 2-4. The proliferation of DPSCs varied significantly according to the electrical stimulation conditions including the current intensity, stimulation time, and rest time. The optimum condition on proliferation of DPSCs for the three electrical stimulation conditions was determined by using the central points of the corresponding contour plots. The results turn out that $38 \mu \mathrm{A}$ is the optimum current condition for DPSC proliferation in our case. We also learned from the response surface plots that there would be a high possibility that the high electric stimulation time or rest time as mES working conditions may be able to increase DPSC proliferation (Figures. 2-4).

To evaluate the optimization results $(38 \mu \mathrm{A})$, we cultured DPSCs with the condition found in this study (i.e., current: $38 \mu \mathrm{A}$; stimulation time: $36.82 \mathrm{sec}$; rest time: $110.46 \mathrm{sec}$ ) for 3 days. As shown in Figure 5, we observed that the DPSCs showed the highest cell proliferation rate when the $38 \mu \mathrm{A}$ was used as a current condition; we learned that approximately $6 \%$ proliferation of DPSCs was increased with the electrical stimulation, compared with ones without electrical stimulation (Figure 5).

To test the hypothesis that mES influences the generation of biochemical elements, we investigated changes in the expressions of secreted proteins using SDS-PAGE. We cultured DPSCs for 3 days with mES, and then we extracted the media by centrifugation at $3000 \mathrm{G}$ in a Centriprep filter with a 3-kDa pore size after culturing DPSCs for 3 days with mES. The conditioned media were resolved by $8 \%$ SDS-PAGE, as shown in Figure 6. Our result showed that the expressions of extracellular proteins induced by mES might influence DPSC proliferation. To verify the SDS-PAGE results on behavior of DPSCs, we cultured DPSCs for 3 days using the conditioned media. 


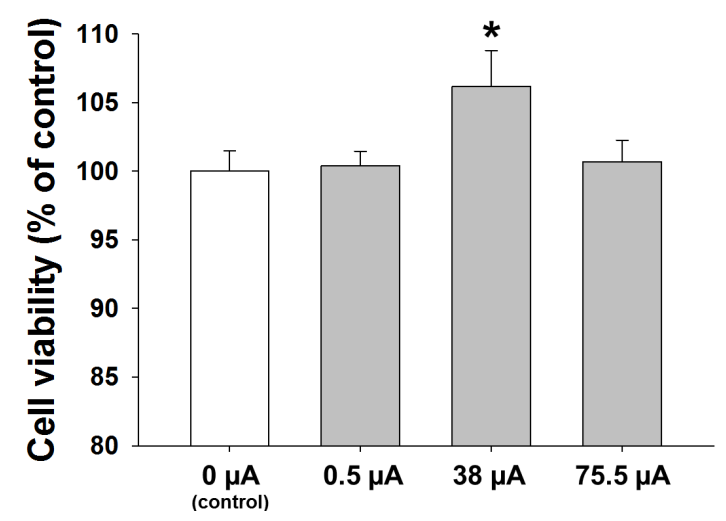

Figure 5. Cell viability assessment to verify the result $\left({ }^{\star} P<0.05\right)$. DPSCs were cultured for 3 days; the DPSCs were stimulated for a total of $2 \mathrm{~h}$ per day (stimulation time: $36.82 \mathrm{sec}$; rest time: 110.46 $\mathrm{sec})$.

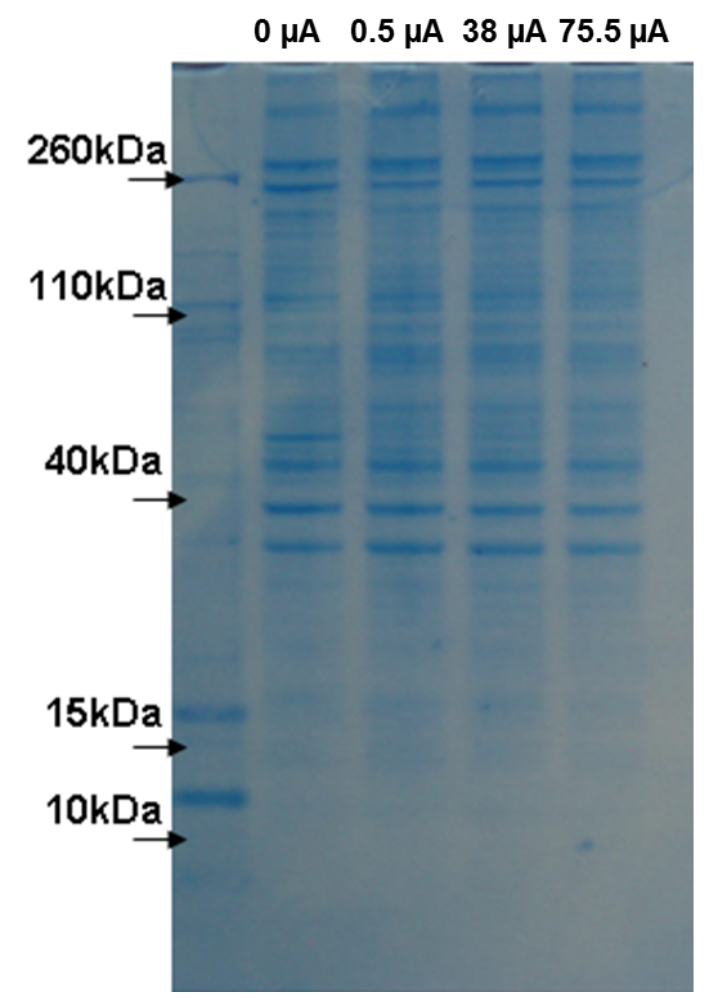

Figure 6. SDS-PAGE of secreted proteins in conditioned media; the conditioned media were obtained from the media cultured DPSCs with electrical stimulation; the conditioned media was collected and extracted by centrifugation at $3,000 \mathrm{G}$ in a Centriprep filter with a 3-kDa pore size.

The highest DPSC cell proliferation rate was observed in medium conditioned at $38 \mu \mathrm{A}$, compared with $0,0.5$, or $75.5 \mu \mathrm{A}$ (Figure 7). This result indicated that some secreted proteins cause mES-induced DPSC proliferation.

Based on our findings, mES is a promising technique for obtaining a number of stem cells. In this study, we tried to use $\mathrm{mES}$ as new method for promoting proliferation

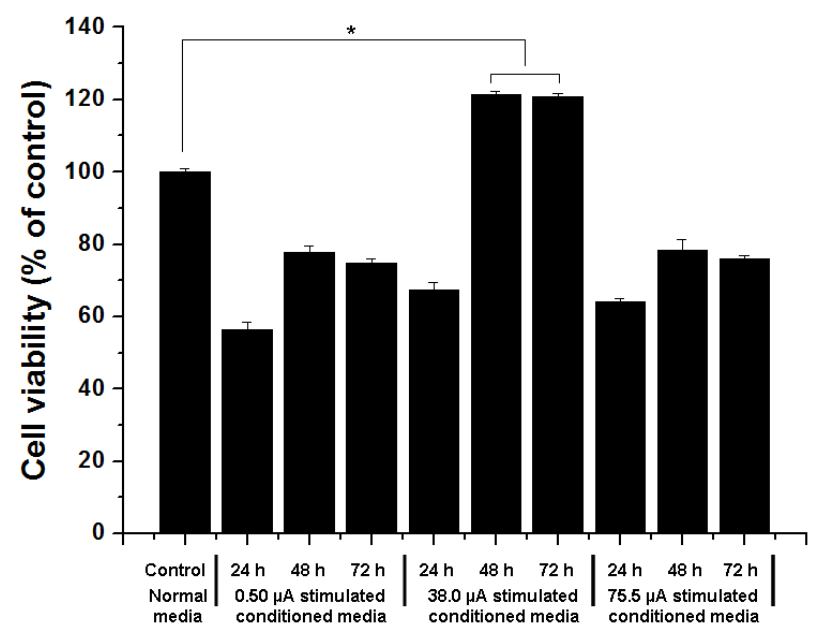

Figure 7. DPSC proliferation in the electro-stimulated conditioned media. This result indicates that the electro-stimulated conditioned media may contain some secreted factor that induces DPSC proliferation.

of DPSCs without using chemical agents, such as serum. We first assayed the proliferation of DPSCs stimulated by mES. Though a more detailed study should determine the optimal mES conditions for DPSC proliferation and plasticity, our data indicate that mES is an efficient method to proliferate DPSCs (Figure 5). Culturing DPSCs with conditioned media from cells grown with mES suggests that $\mathrm{mES}$ influences the expressions of extracellular molecules in DPSCs (Figure 6). We demonstrated that DPSC proliferation can be controlled without serum using mES, suggesting that combining structural and chemical cues with mES may have more potential for the promoting proliferation of DPSCs.

DPSC-based biological engineering requires methods to differentiate stem cells into specific lineages. Physical cues are essential factors for stem cell differentiation (Kim et al. 2009; Kim et al. 2009). Therefore, as a preliminary study, we investigated mES as a method to differentiate DPSCs. In particular, we assayed osteocalcin (OCN) as a marker of osteogenesis, since DPSCs have potential applications in animal and human bone regeneration (Gronthos et al. 2000; Jo et al. 2007; Wang et al. 2011). Although more detailed investigations are necessary, our data indicated that $\mathrm{mES}$ increased $\mathrm{OCN}$ expression in DPSCs (Figure 8). As shown in Figure 8A, by changing the expressions of extracellular or intracellular molecules, mES may facilitate osteogenesis in DPSCs (Figure 8B and $\mathrm{C})$. On the other hand, high intensity $\mathrm{mES}(75.5 \mu \mathrm{A})$, decreased OCN expression. Together, our data suggest that mES may be an efficient method to regulate DPSC 

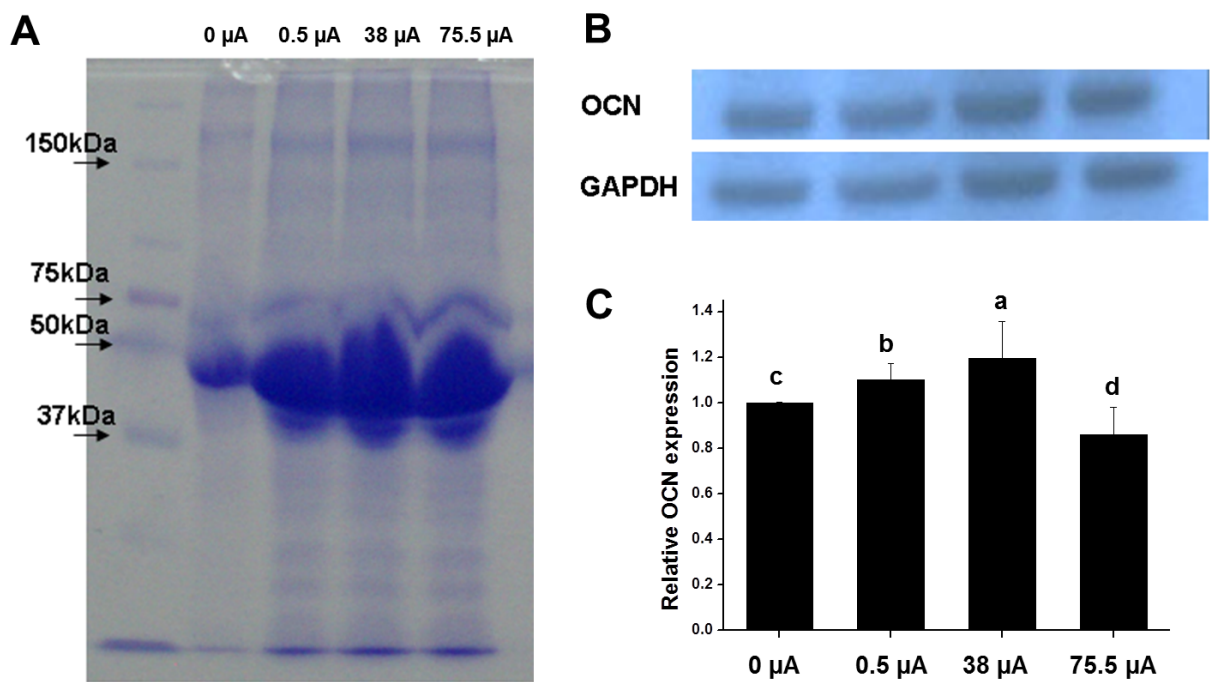

Figure 8. Effects of DPSCs on intracellular molecules and enhanced osteogenic differentiation of DPSCs by electrical stimulation. (A) SDS-PAGE of secreted proteins in electro-stimulated DPSCs. (B) Western blotting for OCN and (C) quantification of OCN expression at 14 days; "a-d" means that the results are significantly different among the different results. The DPSCs were stimulated for a total of 2 h per day (stimulation time: $36.82 \mathrm{sec}$; rest time: $110.46 \mathrm{sec}$ ).

differentiation although the further study is needed. In other words, further studies identifying optimal mES conditions for the regulation of DPSC differentiation would be more beneficial.

\section{Conclusions}

In this study, we demonstrated that mES can regulate the behavior of DPSCs. We found a working micro-current of $38 \mu \mathrm{A}$ as a suitable mES condition using response surface analysis, demonstrating that the mES could induce proliferation of DPSCs. Our results also indicate that the osteogenesis of DPSCs could be improved by using the mES without use of induction chemicals. In addition, we showed that the $\mathrm{mES}$ altered the expressions of intracellular and extracellular proteins compared to those in unstimulated DPSCs. Though further studies on the use of mES to modulate DPSC behaviors are needed, we conclude that mES may be an efficient method to facilitate or regulate DPSC proliferation and differentiation, with applications to DPSCs-based human or animal tissue regeneration.

\section{Conflict of Interest}

No potential conflict of interest relevant to this article was reported.

\section{Acknowledgements}

This study was carried out with the financial support of the Agricultural Research and Development Promotion Center (312031-3), Republic of Korea.

\section{References}

Aaron, R. K., D. M. Ciombor, H. Keeping, S. Wang, A. Capuano and C. Polk. 1999. Power frequency fields promote cell differentiation coincident with an increase in transforming growth factor- $\beta 1$ expression. Bioelectromagnetics 20(7):453-458.

Aaron, R. K., S. Wang and D. M. Ciombor. 2002. Upregulation of basal TGF $\beta 1$ levels by EMF coincident with chondrogenesis-implications for skeletal repair and tissue engineering. Journal of orthopaedic research 20(2):233-240.

Au, H. T. H., B. Cui, Z. E. Chu, T. Veres and M. Radisic. 2009. Cell culture chips for simultaneous application of topographical and electrical cues enhance phenotype of cardiomyocytes. Lab on a Chip 9(4):564-575.

Baumann, S. B., D. R. Wozny, S. K. Kelly and F. M. Meno. 1997. The electrical conductivity of human cerebrospinal fluid at body temperature. Biomedical Engineering, IEEE Transactions on 44(3):220-223.

Berg, H. 1995. Possibilities and problems of low frequency weak electromagnetic fields in cell biology. 
Bioelectrochemistry and bioenergetics 38(1):153-159.

Falanga, V., G. Bourguignon and L. Bourguignon. 1987. Electrical stimulation increases the expression of fibroblast receptors for transforming growth factorbeta. J Invest Dermatol 88(4):4-6.

Gronthos, S., M. Mankani, J. Brahim, P. G. Robey and S. Shi. 2000. Postnatal human dental pulp stem cells (DPSCs) in vitro and in vivo. Proceedings of the National Academy of Sciences 97(25):13625-13630.

Haddad, J. B., A. G. Obolensky and P. Shinnick. 2007. The biologic effects and the therapeutic mechanism of action of electric and electromagnetic field stimulation on bone and cartilage: new findings and a review of earlier work. The Journal of Alternative and Complementary Medicine 13(5):485-490.

Jo, Y.-Y., H.-J. Lee, S.-Y. Kook, H.-W. Choung, J.-Y. Park, J.-H. Chung, Y.-H. Choung, E.-S. Kim, H.-C. Yang and P.-H. Choung. 2007. Isolation and characterization of postnatal stem cells from human dental tissues. Tissue engineering 13(4):767-773.

Kim, D.-H., P. K. Wong, J. Park, A. Levchenko and Y. Sun. 2009. Microengineered platforms for cell mechanobiology. Annual review of biomedical engineering 11:203-233.

Kim, I. S., J. K. Song, Y. L. Zhang, T. H. Lee, T. H. Cho, Y. M. Song, D. K. Kim, S. J. Kim and S. J. Hwang. 2006. Biphasic electric current stimulates proliferation and induces VEGF production in osteoblasts. Biochimica et Biophysica Acta (BBA)-Molecular Cell Research 1763(9):907-916.

Kim, J., Y. R. Kim, Y. Kim, K. T. Lim, H. Seonwoo, S. Park, S. P. Cho, B. H. Hong, P. H. Choung, T. D. Chung, Y. H. Choung and J.H. Chung. 2013. Graphene-incorporated chitosan substrata for adhesion and differentiation of human mesenchymal stem cells. Journal of Materials Chemistry B 1(7): 933-938.

Kim, J. H., C. S. Cho, Y. H. Choung, K.T. Lim, H. M. Son, H. Seonwoo, S. J. Baik, J. Y. Park, P. H. Choung and J. H. Chung. 2009. Mechanical stimulation of mesenchymal stem cells for tissue engineering. Tissue Engineering and Regenerative Medicine 6(1):199-206.

Li, X., T. Xu, X. Ma, K. Guo, L. Kai, Y. Zhao, X. Jia and Y. Ma. 2008. Optimization of culture conditions for production of cis-epoxysuccinic acid hydrolase using response surface methodology. Bioresource technology 99(13): 5391-5396.

Lim, K. T., J. H. Kim, S. Hoon, J. U. Chang, H. C. Choi, J. Hexiu, W. J. Cho, P. H. Choung andJ. H. Chung. 2013. Enhanced osteogenesis of human alveolar bone-derived mesenchymal stem cells for tooth tissue engineering using fluid shear stress in a rocking culture method. Tissue Engineering Part C: Methods 19(2):128-145.

Richardson, L. E., J. Dudhia, P. D. Clegg and R. Smith. 2007. Stem cells in veterinary medicine-attempts at regenerating equine tendon after injury. Trends in biotechnology 25(9):409-416.

Tandon, N., A. Marsano, R. Maidhof, K. Numata, C. Montouri-Sorrentino, C. Cannizzaro, J. Voldman and G. Vunjak-Novakovic. 2010. Surface-patterned electrode bioreactor for electrical stimulation. Lab on a Chip 10(6):692-700.

Wang, J., H. Ma, X. Jin, J. Hu, X. Liu, L. Ni and P. X. Ma. 2011. The effect of scaffold architecture on odontogenic differentiation of human dental pulp stem cells. Biomaterials 32(31):7822-7830.

Zhao, M., A. Dick, J. V. Forrester and C. D. McCaig. 1999. Electric field-directed cell motility involves upregulated expression and asymmetric redistribution of the epidermal growth factor receptors and is enhanced by fibronectin and laminin. Molecular biology of the cell 10(4):1259-1276.

Zhuang, H., W. Wang, R. M. Seldes, A. D. Tahernia, H. Fan and C. T. Brighton. 1997. Electrical stimulation induces the level of TGF- $\beta 1$ mRNA in osteoblastic cells by a mechanism involving calcium/calmodulin pathway. Biochemical and biophysical research communications 237(2):225-229. 